ZS Research Square

\title{
Diversity of Endophytic Bacteria Associated with Different Cultivars of Medicinal Plant Arctium Lappa L. and Their Potential for Host Plant Growth Promoting
}

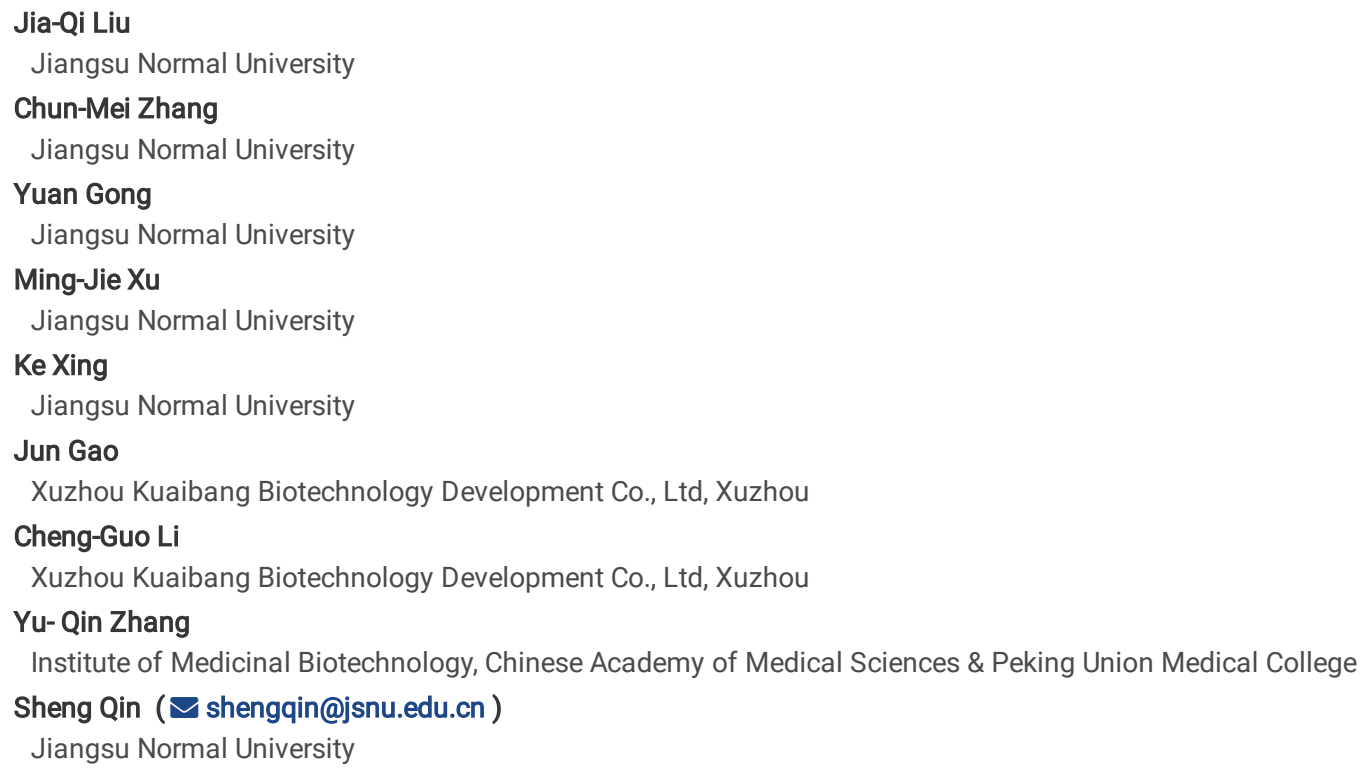




\section{Abstract \\ Purpose}

Arctium lappa L. is one of the medicinal and food homologous plants in China, which is rich in nutrients and medicinal ingredients. The use of plant growth promoting (PGP) endophytic bacteria is a useful alternative in agricultural production to reduce the use of chemical fertilizers. The aim of this study was to analysis the diversity of endophytic bacteria in different cultivars of $A$. lappa L. collected from two different geographical locations in China and evaluate PGP traits of the isolates and their potential PGP ability in greenhouse condition.

\section{Methods}

Endophytic bacterial community was investigated by culture-dependent and culture-independent methods. Isolates were screened and investigated for multiple PGP traits, and representative strains were inoculated host seedlings to evaluate the growth promoting effect.

\section{Results}

A total of 348 endophytic bacteria were obtained and they distributed into four phyla, 30 genera and 73 different species. In addition, high throughput sequencing revealed more abundant bacterial community, including 17 bacterial phyla, and 207 different known genera. A high proportion of PGP traits were detected, including production of indole acetic acid, siderophore, ammonia and phosphate solubilization. Four representative strains with multiple PGP traits of the most prevalent genera were further selected for host inoculation and growth promoting evaluation, and they significantly increase seedlings length, root length and fresh weight.

\section{Conclusion}

This study demonstrated that $A$. lappa L. harbors abundant endophytic bacteria, and plant genotype and geographical origin affect their composition. Moreover, some endophytic bacteria showed good potential for the development of microbial fertilizer in the future.

\section{Introduction}

Arctium lappa L. is not only a medicinal plant, but also a delicious vegetable. Its root is edible and rich in amino acids, polyphenols, polysaccharides, volatile oil, flavonoids and other nutrients and chemical components (Gao et al. 2018; Chen et al. 2020). At the same time, roots and seeds of Arctium lappa L. are also traditional Chinese medicine, which have antibacterial, anti-tumor, anti-virus, immune regulation and other pharmacological effects (Chan et al. 2011; Li et al. 2019). Arctium lappa L. is widely planted in China, and $80 \%$ of total output is exported every year. It is one of the favorite medicinal and food homologous plants, especially in China, Japan and other Eastern Asian countries. A large amount of nitrogen fertilizer is needed in the process of planting and growth of Arctium lappa L. However, the long-term use of chemical fertilizers and continuous cropping will lead to soil hardening, disease and pest increase, continuous cropping barrier and yield decline (Huang et al. 2016). Thus, the use of environmentally friendly biological fertilizer is urgently needed, and the introduction of beneficial microorganisms to plant growth and disease inhibition is recognized worldwide (Bargaz et al. 2018; Phour et al. 2020; Chialva et al. 2021).

Endophytic bacteria are important components of plant microecology. They widely live in the intercellular space of host plants without causing any obvious disease symptoms (Qin et al. 2011; Santoyo et al. 2016). Endophytic bacteria can improve the growth of plants and protect them under biotic and abiotic stresses, e.g. pathogens, pests, salinity, drought, heavy metals, and organic pollutants (Qin et al. 2017; Etesami et al. 2018; Zhang et al. 2019; Xiong et al. 2020b; Harman et al. 2021; Kidd et al. 2021). Plant growth promoting (PGP) induced by endophytic bacteria includes direct mechanisms, such as nitrogen fixation, phosphate/potassium solubilization, production of phytohormones, volatile organic compounds and extracellular polysaccharides, and indirect ways like secretion of siderophores, 1-aminocyclopropane-1-carboxylic acid (ACC) deaminase, antibiotics, extracellular hydrolytic enzymes, and inducing systemic resistance of plants (Liotti et al. 2018; Xiong et al. 2020a; Li et al. 2020; Mathur and Roy, 2021; Jain et al. 2021). Endophytic bacteria have been proved to play important roles in the growth of crops and some medicinal plants (Qin et al. 2018; Costa Júnior et al. 2020; Krishnamoorthy et al. 2020; Wu et al. 2021). For example, endophytic bacteria from Lavandula dentata significantly increased adventitious root formation and the rooting capacity of cuttings (Pereira et al. 2016). Endophytic bacteria from the roots of the medicinal plant Alkanna tinctoria Tausch induce alkannin and shikonin production in host hairy roots (Rat et al. 2021). Some endophytic actinobacteria from roots and nodules of chickpea (Cicer arietinum) were found to promote host growth and nodulation in a low $\mathrm{N}$ sand-vermiculite system (Vo et al. 2021). In recent years, the composition of abundant and diverse endophytic bacteria has been revealed by pure culture isolation and modern high-throughput sequencing technology. Generally, Bacillus, Streptomyces, Pantoea, Pseudomonas Microbacterium, Burkholderia, Micrococcus and Stenotrophomonas were detected as the most common bacteria, where Bacillus and Pseudomonas are the predominant genera (Afzal et al. 2019; Papik et al. 2020). However, compared with nearly 300,000 species of plants on earth (Ryan et a. 2008), the known composition and diversity of endophytic bacteria is the 'tip of the iceberg'. Therefore, it is necessary to understand the community composition of endophytic bacteria associated with different medicinal plants and their ecological function and application potential in host growth.

The objective of this study is: (1) to isolate and identify endophytic bacteria from different cultivars of Arctium lappa L.; (2) to analyze the composition and diversity of endophytic bacteria from different cultivars and different geographical sources by combined culture-dependent and high-throughput sequencing 
methods; (3) to evaluate the plant growth-promoting traits of the isolates, such as indole acetic acid (IAA), siderophores production, nitrogen fixation and phosphate solubilization, and the effects on the growth of host plants seedlings of selected strains in greenhouse soil.

\section{Materials And Methods}

\section{Sample collection}

Healthy different cultivars of Arctium lappa L (roots, stems and leaves). were collected from fields of two different geographical locations in China. Three cultivars: Jike (NB1), Liuchuan lixiang (NB2), and Dongbei lixiang (NB3) were collected from the same field in Xuzhou city, eastern China $\left(116^{\circ} 51^{\prime} 59^{\prime \prime} \mathrm{E} ; 34^{\circ} 33^{\prime} 10^{\prime \prime} \mathrm{N}\right)$, the fourth sample (Dongbei lixiang, NB4) was obtained from fields of the city Harbin $\left(127^{\circ} 29^{\prime} 56^{\prime \prime} \mathrm{E} ; 45^{\circ} 16^{\prime} 43^{\prime \prime} \mathrm{N}\right)$ in northeast of China. All the samples were collected and brought back to the laboratory immediately and were stored at $4{ }^{\circ} \mathrm{C}$ and $-20^{\circ} \mathrm{C}$.

\section{Isolation of endophytic bacteria}

Plant samples were washed with tap water and surface sterilized according to the previously described procedures (Qin et al. 2009). Specifically, samples were firstly soaked in sterile $0.01 \%$ Tween 20 for $1 \mathrm{~min}$, and then soaked in $5 \% \mathrm{NaClO}$ (effective chlorine content) for 3 min for roots, 2 min for stems and leaves, followed by treating with sterile $2.5 \% \mathrm{Na}_{2} \mathrm{~S}_{2} \mathrm{O}_{3}$ for $10 \mathrm{~min}$, and then washed with sterile water for 3 times. After that, samples were soaked in $75 \%$ ethanol for $2 \mathrm{~min}$ for roots and stems, and $1 \mathrm{~min}$ for leaves, and final washing 3-5 times with sterile water. In order to check the reliability of surface disinfection, the sterile water used in the last step was absorbed and spread onto LB and ISP 2 agar media, and the plates were cultured at $30{ }^{\circ} \mathrm{C}$ for one week to observe whether there were colonies present. If not, the surface disinfection was complete. Then, sterilized tissues were aseptically grinded into smaller fragments using a commercial blender and then spread onto different isolation media.

Ten different media were used for endophytes isolation. M1: TWYE agar (Coombs and Franco, 2003); M2: trehalose-proline medium (Qin et al. 2014); M3: CMC agar (Kaewkla and Franco, 2013); M4: ISP 5 medium (Shirling and Gottlieb, 1966); M5: starch-casein agar medium (Xing et al. 2012); M6: sodium propionate agar (Qin et al. 2009); M7ØXylan-amino acid agar [Xylan $2.0 \mathrm{~g},\left(\mathrm{NH}_{4}\right)_{2} \mathrm{SO}_{4} 1.0 \mathrm{~g}, \mathrm{CaCl}_{2} 2.0 \mathrm{~g}, \mathrm{~K}_{2} \mathrm{HPO}_{4} 0.5 \mathrm{~g}$, amino acid mixture $1.0 \mathrm{~g}$, agar $15.0 \mathrm{~g}$, $\mathrm{H}_{2} \mathrm{O} 1000$ mL, pH 7.2]; M8: nutrient agar (peptone $5 \mathrm{~g}$, beef extract $2 \mathrm{~g}$, agar $18 \mathrm{~g}, 1$ L distilled water, pH 5.0); M9: Luria-Bertani (LB) agar medium; M10: TSA medium (Tryptone $15.0 \mathrm{~g}$, soybean peptone $5.0 \mathrm{~g}, \mathrm{NaCl} 5.0 \mathrm{~g}$, agar $18 \mathrm{~g}, 1 \mathrm{~L}$ distilled water, $\mathrm{pH}$ 7.0). Among them, M1-M7 media were used to isolate actinomycetes, supplemented with nystatin $\left(50 \mathrm{mg} \mathrm{l}^{-1}\right)$ and nalidixic acid (50 mg l-1 ); M8-M10 media were used to isolate bacteria, supplemented with nystatin $\left(50 \mathrm{mg} \mathrm{l}^{-1}\right)$. Plates were incubated at $28^{\circ} \mathrm{C}$ for $1-4$ weeks, and the colonies were obtained and purified, and then maintained on slants at $4^{\circ} \mathrm{C}$.

\section{Identification of the culturable endophytic bacteria}

The isolated strains were firstly classified and dereplicated according to their phenotypic characteristics, including colony color, morphology, and presence of sterile hyphae and pigment, and the culture characteristics. Then, selected representative strains were identified by 16S rRNA gene sequencing. The total DNA extraction and 16S rRNA gene amplification was conducted according to the previous method (Li et al. 2007). The primers 27F (5'-

GAGTTTGATCACTGGCTCAG-3') and 1492R (5'-TACGGCTACCTTGTTACGACTT-3') were used to amplify 16S rRNA gene. Then, 16S rRNA gene sequence were compared in NCBI and EzTaxon-e database (Kim et al. 2012) to obtain the nearest type strains and the similarities. All the 16S rRNA gene sequences were deposited at GenBank of NCBI database under the accession numbers MW186019-MW186145.

\section{Endophytic bacterial diversity by high throughput sequencing (HTS) method}

The number of endophytic bacteria isolated from roots was the largest, thus we continue to analyze the composition of uncultured endophytic bacteria in roots of A. lappa L. by high-throughput sequencing. Healthy roots samples of NB1-NB4 were firstly surface sterilized as described above. Then, about $0.5 \mathrm{~g}$ tissues of each sample were used for total DNA extraction by Shanghai Majorbio Biotechnology Co., Ltd. (Shanghai, China).

Endophytic bacterial 16S rRNA genes were amplified using the 799F (5'-AACMGGATTAGATACCCKG-3') and 1115R (5'-AGGGTTGCGCTCGTTG-3') primers pair (Chelius and Triplett, 2001; Reysenbach and Pace, 1995) according to the detailed PCR amplification procedure described recently (Chen et al. 2019). Purified PCR products were then quantified using the QuantiFluor ${ }^{\text {TM }}-$ ST (Promega, U.S.) system. Amplicons were pooled in equimolar concentrations and paired-end sequenced $(2 \times 250)$ on an Illumina MiSeq platform at Majorbio Biotech Co., Ltd (Shanghai, China) according to standard protocols. The sequenced reads of the four samples were deposited in the Sequence Read Archive (SRA) of NCBI database under the accession number PRJNA670781.

After pre-processed and quality-filtered of raw reads by using QIIME v.1.17 software (http://qiime.org), the 16S rRNA gene sequences were subjected to cluster analysis of Operational Taxonomic Units (OTUs) at the $97 \%$ similarity according to the UPARSE v.7.1 software (http://drive5.com/uparse/). Then, chimera filtering was carried out by using the UCHIME v. 4.2 .40 program ( http://drive5.com/usearch/manual/uchime_algo.html). The phylogenetic affiliation of the 16S rRNA gene sequences of each OTU was assessed using the RDP Classifier (http://rdp.cme.msu.edu/) and comparison against the SILVA (SSU117/119, https://www.arb-silva.de/) 16S rRNA gene database while using a confidence threshold of 70\%. The rarefaction curves of each sample were plotted to estimate the sequencing depth and endophytic bacterial abundance. Alpha diversity and richness indices (Chao, Ace, Simpson and Shannon) were calculated by MOTHUR software (version 1.30.1).

\section{Plant growth promotion traits evaluation of culturable endophytic bacteria}

The PGP traits of the 140 representative strains, including indole acetic acid (IAA) production, siderophore production, ACC deaminase production, ammonia production, phosphate solubilization, nitrogen fixation and hydrolase production were determined according to the standard procedures. Nitrogen fixation potential was examined by observing the growth on $\mathrm{N}$-free semi-solid JNFb medium (Döbereiner et al. 1995) and both positive PCR amplification of nifH gene 
using the primer pair PolF/PolR and related PCR conditions (Poly et al. 2001). Indole acetic acid (IAA) production was qualitatively evaluated by cultivating strains in minimal salts medium supplemented with $0.5 \mathrm{mg} / \mathrm{ml}$ of tryptophan and detection via Salkowsky's reagent (Gordon and Weber, 1951), and quantitative analysis was performed by using the standard curve of IAA standard. Siderophore, ACC deaminase production and phosphate solubilization was checked by using standard Chrome Azurol-S (CAS) assay (Schwyn and Neilands, 1987), DF minimal medium (Penrose and Glick, 2003), and Ca 3 (PO $)_{2}$ solubilization agar medium (Franco-Correaa et al. 2010), respectively. For ammonia production examination, strains were cultured into 5 ml liquid medium containing $10 \mathrm{~g} / \mathrm{L}$ peptone, incubating at $28^{\circ} \mathrm{C}(120 \mathrm{rpm})$ for $72 \mathrm{~h}$. Then, $0.5 \mathrm{ml}$ Nessler's reagent (Rashid et al. 2012) was added to check if yellow brown precipitate was produced. The amylase, chitinase, xylanase, protease and cellulase activities was screened by inoculated the strains on the starch agar (Hols et al. 1994), minimal medium agar supplemented with $0.6 \%$ (w/v) colloidal chitin and xylan (Chernin et al. 1995), skim milk agar (Krechel et al. 2002), and carboxymethyl cellulose agar containing $0.2 \%$ (w/v) Congo red (El-Sayed et al. 2014; Gong et al. 2018). The activities were qualitatively evaluated by the presence of a clear zone around the colony after incubating for 7 days at $28^{\circ} \mathrm{C}$.

\section{Seeds inoculation with bacterial endophytes and evaluation of PGP effects in greenhouse}

Four representative endophytic bacteria WY035 (Bacillus sp.), WY068 (Pantoea sp.), WY358 (Microbacterium sp.), and WY297 (Pseudomonas sp.) with multiple PGP characteristics were used to inoculate host seeds. These strains were cultured in LB liquid medium for 24-48 $\mathrm{h}$, and then cells were harvested by centrifugation at $5000 \mathrm{rpm}$ for $10 \mathrm{~min}$. The cells were adjusted to different densities with sterile water, with $\mathrm{OD}_{600} 0.25-1.0$ for different strains. $A$. lappa $\mathrm{L}$. seeds were sterilized with $5 \% \mathrm{NaClO}$ for $5 \mathrm{~min}$, following washing with sterile water for 3-4 times, and then soaked in endophytic bacterial suspension for 20 $\mathrm{h}$, and the control was soaked in sterile water for $20 \mathrm{~h}$. The treated seeds were directly planted in pots (one seed per pot), which were filled with $200 \mathrm{~g}$ sterilized soil. Then, all the pots were transferred to the greenhouse $\left(25^{\circ} \mathrm{C} / 20^{\circ} \mathrm{C}, 16 / 8 \mathrm{~h}\right.$ light/dark), and each treatment consisted of ten biological replicates During seedling growth, the treatment and control groups were watered normally. After 45 days of growth, the growth parameters (total length, fresh weight and root length) of the seedlings were evaluated.

\section{Statistical analysis}

The experimental results were expressed by mean values and standard deviation (SD) for three or five independent replicates as specified. Data were analyzed by analysis of variance (ANOVA) and Student's t-tests at $P<0.05$. Excel and GraphPad Prism 5.0 were used for data analysis and mapping.

\section{Results}

\section{Isolation of endophytic bacteria}

A total of 348 endophytic bacteria were isolated from different tissues of Arctium lappa L. using ten different isolation media, of which 108 strains were from NB1 (roots, stems and leaves), 116 strains were from NB2 (roots, stems and leaves), 86 strains were from roots of NB3, and 38 strains were from roots of NB4. There were 230 strains in roots, 68 strains in leaves, and 52 strains in stems, respectively. Comparing the isolation efficiency of different media, we found that M8-M10 media included the most isolated bacteria, with 112, 84, and 65 strains, respectively (Fig. 1A), whereas 87 endophytic bacterial strains were obtained from the other seven different media.

\section{Identification and diversity of culturable endophytic bacteria}

By observing the morphology and color of colonies, mycelial and spore characteristics on ISP 2 and LB agar media, we compared the phenotypes of obtained 348 strains. The morphology and culture characteristics of some representative strains are shown in Figure S1. Based on the phenotypic dereplication, 140 strains (108 from roots, 16 from stems, and 16 from leaves) were carried out detailed identification via 16S rRNA gene sequencing. The similarity between the sequenced strains and their most recent type strains was $99-100 \%$. One strain, WY0036, showed only $97.83 \%$ similarity $(1,460$ bp) with the type strain Sphingobacterium composti $\mathrm{T} 5-12^{\top}$, indicating its status of a potential new species (Table S1). These strains belonged to the four phyla: Actinobacteria (67.24\%), Proteobacteria (22.86\%), Firmicutes (9.29\%) and Bacteroidetes (0.71\%) (Fig. 2A), and Actinobacteria was the most predominant among the endophytic bacteria. All the sequenced strains distributed into 30 genera and 73 different species (Table S1), including 18 genera in Actinobacteria, such as Amycolatopsis, Arthrobacter, Brachybacterium, Cellulosimicrobium, Corynebacterium, Gordonia, Leucobacter, Microbacterium, Micrococcus, Nocardia, Nonomuraea, Plantibacter, Promicromonospora, Pseudoclavibacter, Pseudonocardia, Rhodococcus, Streptomyces and Tsukamurella. There are nine genera in Proteobacteria, including Brevundimonas, Methylobacterium, Rhizobium, Sphingomonas, Achromobacter, Cedecea, Enterobacter, Pantoea and Pseudomonas. There are two genera of Bacillus and Staphylococcus in Firmicutes and only one genus in the phylum Bacteroidetes (Fig. 3B). At the genus level, Streptomyces (22 isolates), Microbacterium (20 isolates), Promicromonospora (16 isolates), Bacillus (12 isolates), Pseudomonas (8 isolates) and Arthrobacter (8 isolates) were the most dominant genera (Fig. 2B).

The composition of endophytic bacteria in A. lappa L. was also affected by plant cultivars and geographical origin (Fig. $2 \mathrm{C}$ and $\mathrm{D}$ ). At the phylum level, there is little difference in bacterial composition, and the most abundant is Actinobacteria, followed by Proteobacteria and Firmicutes (Fig. 2C). At the genus level, 18, 14, 11 and 18 different bacterial genera were obtained from the four samples, respectively (Fig. 1B and Table S2). However, plant cultivars and geographical factors affect the distribution of culturable endophytic bacteria. The genera Bacillus, Microbacterium, Pseudomonas and Streptomyces were common in the four samples. Among the three A. lappa L. cultivars sampled from Xuzhou, all the most dominant genera were Microbacterium and Streptomyces. However, abundant Promicromonospora was isolated from NB3 cultivar and rarely obtained from other samples. The genera Arthrobacter, Microbacterium and Pseudoclavibacter were found abundant in the Harbin sample NB4, which is different from the mainly composition of three Xuzhou samples (Fig. 2D). 
A total of 145,525 quality-filtered reads were obtained from four root samples (27,380-52,573 per sample). Root of NB3 harbors the most abundant OTUs (494) at the species level. The number of OTUs in other samples were 332, 449, and 221 for NB1_R, NB2_R and NB4_R, respectively. Diversity coverage estimations indicated more than $99.0 \%$ of bacteria was sequenced. Moreover, rarefaction analyses indicated that the curves nearly reached asymptotes, suggesting that measured diversity was nearly saturated (Fig. 3A). Alpha diversity indices were calculated and indicated that community diversity differentiate across the for roots samples, with NB2 and NB3 roots harbored more abundant bacterial endophytes (Table 1). A total of 100 0TUs were common present across four samples. In contrast, OTUs that were exclusive to each root tissue ranged from 43 to 141. NB3_R harbored the highest numbers of unique OTUs, followed by NB2_R and NB4_R (Fig. 3B).

The distribution of endophytic bacteria at the phylum level in different root samples is shown in Fig. 4C. A total of 17 phyla of bacteria were detected, among which Proteobacteria (47.98\%-96.72\%) was the most dominant, followed by Firmicutes, Actinobacteria, Bacteroidetes and Cyanobacteria. The phyla Firmicutes (23.03\% and 32.02\%) and Actinobacteria (6.843\% and 12.01\%) in NB2_R and NB3_R samples showed much higher relative abundance than other two samples (Fig. 3C). The composition of endophytic bacteria in different roots varied greatly at genus level. A total of 207 different known genera were detected by HTS technique. In addition to the unclassified genera, the genus Pantoea accounted for $53.19 \%$ in NB1, and Pseudomonas was the most abundant genus in NB2 and NB4 samples, accounting for 19.24\% and 76.94\% respectively, whereas Hyphomicrobium was more abundant in NB2, accounting for $7.35 \%$ (Fig. 3D). Except for the unclassified genera, the top ten core genera in each root tissue are shown in Table 2 . We found that Pseudomonas, Bacillus, Pandora and Streptomyces were distributed in almost all samples, and they were the most common genera in A. lappa L. roots.

Phylogenetic affiliation of the 16S rRNA gene sequences revealed more abundant endophytic bacteria than those obtained by pure culture method. Specifically, only 4 of the 17 phyla detected by HTS technique were obtained by cultivation. At the genus level, 83-154 known genera were found in four kinds of roots, far more than the maximum of 18 genera obtained by pure culture technique (Fig. 1B). Many genera detected by HTS were also obtained by pure culture, including Amycolatopsis, Brachybacterium, Enterobacter, Methylobacterium, Microbacterium, Nonomuraea, Promicronospora, Rhizobium, etc. The core genera, including Pseudomonas, Pantoea, Arthrobacter, Bacillus, Streptomyces, Pseudomonas and Rhizobium, were also cultured by culture-dependent methods. However, some genera were not detected by high-throughput sequencing, such as Achromobacter, Cedecea, Cellulosimicrobium, Nocardia, Plantibacter, Pseudoclavibacter, Rhodococcus, Sphingobacterium and Staphylococcus, which may be related to the quality of DNA extraction and the bias of PCR amplification in high-throughput sequencing.

\section{Plant growth promotion traits of culturable endophytic bacteria}

After checking the PGP traits of the 140 strains, the positive for the ACC deaminase and ammonia production was up to $55 \%$ (77 strains) and $54.3 \%$ (76 strains), respectively, followed by siderophore production (48.6\%, 68 strains), nitrogen fixation $(46.4 \%, 65$ strains), IAA production (41.4\%, 58 strains), and phosphate solubilization ( $26.4 \%, 37$ strains). Comparing the origin of these strains, we found that the endophytic bacteria from NB1 showed the most PGP characteristics, almost all more than 20 strains, followed those from NB2 and NB3, and the number of active strains from NB4 was the least (Fig. 4A). The positive results of representative strains are shown in Fig. 4C. For IAA quantitative detection, the yield of strain Pantoea SP. WY068 was the highest, reaching $37.8 \mathrm{mg} / \mathrm{L}$. In addition, 47 isolates (33.6\%) possessed amylase activity, 46 isolates (32.9\%) possessed cellulase activity, and 45 isolates (32.1\%) possessed protease activity. Whereas xylanase and chitinase producers were 28 isolates (20\%) and 22 strains (15.7\%), respectively. In comparison, NB3 possessed the largest number of enzymes producing bacteria, more than 10 strains for each hydrolytic enzyme (Fig. 4B). The enzyme activity screening of representative strains is shown in Fig. 4D.

\section{Plant growth promoting activity of selected bacterial endophytes}

Four representative endophytic bacteria, WY035 (Bacillus sp.), WY068 (Pantoea sp.), WY358 (Microbacterium sp.), and WY297 (Pseudomonas sp.), which showed multiple PGP characteristics (Table 3) of the most prevalent genera were selected for PGP evaluation. After seeds inoculation and 45 days growth in soil, seedlings growth was evaluated. There was no significant difference in seed germination rate after the treatment of the four strains. However, the results showed that all the strains stimulated the growth of $A$. lappa L. seedlings. Endophytes treated seedlings showed significant increase $(P<0.05)$ in seedlings length, root length and fresh weight (Fig. 5). The former three strains exhibited the highest PGP activities, and their results in pots were shown in Fig. 5D. Seedlings length was increased by $68.3 \%$ and $69.4 \%$, respectively, after WY035 and WY068 inoculation (Fig. 5A). In addition, isolates WY068 and WY035 also greatly increased the root lengths by $133.9 \%$ and $94.3 \%$, respectively (Fig. 5B). Furthermore, the fresh weight of the seedlings was increased at least by 4.5 folds in the presence of the endophytes (Fig. 5C).

\section{Discussion}

Plants harbor abundant endophytes, and a variety of endophytic bacteria have been detected by culture-dependent and culture-independent methods. According to the statistics by Hardoim et al. (2015), a total of 21 bacterial phyla of endophytes were identified, which mainly includes Proteobacteria, Actinobacteria, Firmicutes, and Bacteroidetes. In addition, endophytic bacteria have various functions, such as promoting growth, inhibiting phytopathogens, enhancing plant fitness under biotic and abiotic stress (Afzal et al. 2019; Ullah et al. 2019; Rana et al. 2020), thereby have important application potential in plant growth and agriculture. At present, most of the studies focus on endophytic bacteria from crops and model plants, such as rice, wheat, maize, tomato, Arabidopsis, etc. (Lundberg et al. 2012; Chaudhry et al. 2017; Fadiji et al. 2020; Thomas and Shaik, 2020), but the information of the composition of endophytic bacteria in medicinal and food homologous plants is less available. Endophytic bacteria have been poorly investigated specifically for their potential as PGP agents. To our knowledge, this study is the first detailed investigation on endophytic bacterial community and potential functions from medicinal plant Arctium lappa L. 
In this study, we isolated more than 300 endophytic bacteria strains, including 30 genera and a potential new species, indicating that $A$. lappa L. harbors abundant and diverse endophytic bacteria. According to the literature, there are few reports of endophytic bacterial diversity from a medicinal plant with such high abundance. Taxonomic compositional analysis indicated that these strains distributed into bacterial phyla Actinobacteria, Proteobacteria, Firmicutes and Bacteroidetes. The composition of the endophytes at the phylum level is consistent with various current results (Hardoim et al. 2015; Xu et al. 2019). The main genera obtained, e.g. Bacillus, Pseudomonas, Streptomyces, Microbacterium, and Pantoea have been isolated in other plants (Qin et al. 2015; Gao et al. 2019; Xiong et al. 2020b), indicating that they are common and widely distributed in different plants. Some rare genera, such as Leucobacter, Cedecea, Pseudoclavibacter and Plantibacter have rarely been reported as pure cultures of endophytic bacteria, which may be related to host selection and recruitment effect of endophytic bacteria (Mina et al. 2020). High throughput sequencing technology provides convenience for us to understand the composition of endophytic bacteria. As many as 207 known endophytic bacterial genera some unclassified taxa were detected by HTS technique in this study, which indicated that the diversity of endophytic bacteria in roots was far more than that of pure culture. Only $10.1 \%$ ( 21 genera) of the 207 genera were also obtained by culture-dependent method.

The dominant genera found by cultivation are not completely consistent with HTS technique. For example, HTS revealed abundant OTUs of Pantoea and Pseudomonas, but the number of pure cultures was less. This is related to the selection of isolation method, media used, primer preference for PCR and the extraction efficiency of total environmental DNA. This disparity is consistent with some recent results (Qin et al. 2012; Gong et al. 2018; Chen et al. 2019), indicating that the combination of the two methods can better reveal the diversity of endophytic bacteria. At the same time, the isolation technology needs to be improved and innovated, so as to isolate more functional endophytic bacteria.

It has been found that both biotic factors (plant genotypes, developmental stages and tissues) and abiotic factors (soil, climate, temperature and geographical factors) can affect and drive the structure and composition of endophytic bacteria (Yu et al. 2015; Polivkova et al. 2018; Papik et al. 2020). In this study, cultivars and geographical factors greatly affected the composition of endophytic bacteria in $A$. lappa L., and the difference was more obvious at the genus level. Even for the three cultivars grown in the same field, the dominant genera were different (Fig. 4). This result is consistent with the recent discovery that the composition of endophytic bacteria in different cultivars of mulberry is different (Xu et al. 2019). Besides, 66.1\% of the strains were isolated from the root tissues of A. lappa L., which was similar to many other reports (Qin et al. 2009; Tian and Zhang, 2017). Studies have confirmed that root endophytes mainly come from the rhizosphere soil, and then become endophytes through the recruitment of plant root exudates (Martínez-Romero et al. 2020). Because roots of $A$. lappa L. is the edible part, elucidating the diversity of endophytic bacteria in the roots is helpful to understand their functions and potential roles in plant microecosystem.

Studies have confirmed that endophytic bacteria can promote plant growth through a series of direct and indirect mechanisms, such as nitrogen fixation, IAA secretion, dissolution of phosphorus and potassium, production of siderophore and various hydrolases (Qin et al. 2011; Rana et al. 2020). We found that the isolated endophytic bacteria showed a variety of PGP traits, especially the numbers of IAA and siderophore producers, and nitrogen fixation endophytes were more than $40 \%$ of the detected strains (Fig. 4). The results showed that the endophytic environment of $A$. lappa L. is rich in endophytic bacteria with plant growth promoting function, and the relationship between endophytes and host is worth exploring. We further selected four representative endophytic bacteria of the dominant genera (Bacillus, Pantoea, Pseudomonas and Microbacterium) for seed inoculation, and found that they can significantly promote host growth (Fig. 5), which is mainly due to their multiple PGP characteristics.

Bacillus spp. and Pseudomonas spp. have been widely used in agriculture and plant protection because of their versatile functions, mainly plant growth promoting and biocontrol of plant pathogens (Biessy et al. 2018; Saxena et al. 2020). In this study, endophyte WY035, which showed 100\% 16S rRNA gene similarity with Bacillus velezensis FZB42, a model strain for plant growth promotion and biocontrol (Fan et al. 2018), also significantly promoted host seedlings growth, thereby showing good application potential. Similarly, endophyte Bacillus sp. CW16-5 exhibited the highest promotion capacity in mulberry, which increased host shoot length and the root fresh weight by $83.37 \%$ and $217.70 \%$, respectively (Xu et al. 2019). The genus Pantoea is particular worth mentioning, because it is the dominant genus in NB1 and NB 2 samples detected by high-throughput sequencing. Many endophytic bacteria of this genus have been proved to have antibacterial, plant growth promoting and phytoremediation potential (Marag and Suman, 2018; Song et al. 2020; Mello et al. 2020). We also found that endophyte Pantoea sp. WY068 produced the highest amount of IAA and significantly promoted the growth of host seedlings. Many endophytic bacteria with high IAA yield have been proved to be good plant growth promoting agents (Qin et al. 2014; Afzal et al. 2019).

It is worth noting that the community of endophytic bacteria with multiple PGP characteristics are very abundant in this study, which indicates that it is indeed the microbiota, rather than a single strain, may play a more important role in host growth promoting. At present, the use of simplified and synthetic bacterial community to study plant-microbiome interaction is still in its infancy (Vorholt et al. 2017). However, synthetic microbiome is a good strategy. There have been reports on the construction of simplified plant microbiome, and their functions in plant growth promoting and pathogens biocontrol (Zhuang et al. 2021; Lee et al. 2021; Hansen et al. 2020). For example, a simplified maize microbiome composed of seven $\mathrm{f}$ bacteria was constructed by Niu et al (2017). They found that the simplified microbiome could promote the growth of maize seedlings and significantly inhibit the colonization of pathogen Fusarium verticillioides. Simplified microbiota construction is an important direction of plant microbiome research in the future. Therefore, a simplified microbiome of Arctium lappa L. can be constructed for host growth promotion evaluation and field inoculation verification in the further study.

\section{Conclusion}

In this study, the composition of endophytic bacteria in different cultivars of Arctium lappa L collected from two different geographical locations was analyzed in detail by culture-dependent and 16S rRNA gene high-throughput sequencing techniques. Overall, 348 endophytic bacteria were obtained, and they belonged to four bacterial phyla (Actinobacteria, Proteobacteria, Firmicutes and Bacteroidetes). Results demonstrated that endophytic bacteria associated with A. lappa L., especially in the roots were abundant. In addition, a high proportion of beneficial bacteria with potential growth promoting function were found in the endophytic bacteria, and four representative strains promoted host seedling growth significantly in the pot experiments. Our results provided 
good resources for the subsequent development of biological fertilizers for $A$. lappa L. growth, but the actual promotion effect in the field still needs to be evaluated. Besides, the detailed growth promoting mechanism of single strain and the construction of synthetic bacterial community need to be further studied.

\section{Declarations}

\section{Acknowledgements}

This work was supported by the Promoting Science and Technology Innovation Project of Xuzhou City (KC21130), Natural Science Foundation of the Jiangsu Higher Education Institutions of China (17KJA180004), Qing Lan Project of Jiangsu Province (2019).

\section{Authors' contributions}

Jia-Qi Liu: Investigation, Methodology, Data curation, Formal analysis. Chun-Mei Zhang: Writing - review \& editing. Yuan Gong: Methodology, Data curation, Formal analysis. Ming-Jie Xu: Data curation, Formal analysis. Ke Xing: Writing - review \& editing. Jun Gao: Investigation. Cheng-Guo Li: Investigation. Yu- Qin Zhang: Methodology, Formal analysis. Sheng Qin: Conceptualization, Project administration, Supervision, Funding acquisition, Writing - review \& editing.

\section{Conflict of interest}

The authors declare that they have no conflict of interest.

\section{References}

1. Afzal I, Shinwari ZK, Sikandar S, Shahzad S (2019) Plant beneficial endophytic bacteria: Mechanisms, diversity, host range and genetic determinants. Microbiol Res 221:36-49

2. Bargaz A, Lyamlouli K, Chtouki M, Zeroual Y, Dhiba D (2018) Soil microbial resources for improving fertilizers efficiency in an integrated plant nutrient management system. Front Microbiol 9:1606

3. Biessy A, Filion M (2018) Phenazines in plant-beneficial Pseudomonas spp.: biosynthesis, regulation, function and genomics. Environ Microbiol 20(11):3905-3917

4. Cajthaml T, Macek T, Uhlik O (2018) Diversity of root-associated microbial populations of Tamarix parviflora cultivated under various conditions. Appl Soil Ecol 125:264-272

5. Chan YS, Cheng LN, Wu JH, Chan E, Kwan YW, Lee SM, Leung GP, Yu PH, Chan SW (2011) A review of the pharmacological effects of Arctium lappa (burdock). Inflammopharmacology 19(5):245-254

6. Chaudhry V, Sharma S, Bansal K, Patil PB (2017) Glimpse into the genomes of rice endophytic bacteria: diversity and distribution of firmicutes. Front Microbiol 7:2115

7. Chelius MK, Triplett EW (2001) The diversity of archaea and bacteria in association with the roots of Zea mays L. Microb Ecol 41:252-263

8. Chen M, Xu J, Wang Y, Wang Z, Guo L, Li X, Huang L (2020) Arctium lappa L. polysaccharide can regulate lipid metabolism in type 2 diabetic rats through the SREBP-1/SCD-1 axis. Carbohydr Res 494:108055

9. Chen P, Zhang C, Ju X, Xiong Y, Xing K, Qin S (2019) Community composition and metabolic potential of endophytic actinobacteria from coastal salt marsh plants in Jiangsu, China. Front Microbiol 10:1063

10. Chernin L, Ismailov Z, Haran S, Chet I (1995) Chitinolytic Enterobacter agglomerans antagonistic to fungal plant pathogens. Appl Environ Microbiol 61:1720-1726

11. Chialva M, Lanfranco L, Bonfante P (2021) The plant microbiota: composition, functions, and engineering. Curr Opin Biotechnol 73:135-142

12. Coombs JT, Franco CMM (2003) Isolation and identification of actinobacteria from surface-sterilized wheat roots. Appl Environ Microbiol 69:5603-5608

13. Costa Júnior PSP, Cardoso FP, Martins AD, Teixeira Buttrós VH, Pasqual M, Dias DR, Schwan RF, Dória J (2020) Endophytic bacteria of garlic roots promote growth of micropropagated meristems. Microbiol Res 241:126585

14. Döbereiner HG, Evans E, Seifert U, Wortis M (1995) Spinodal fluctuations of budding vesicles. Phys Rev Lett 75:3360-3363

15. El-Sayed WS, Akhkha A, El-Naggar MY, Elbadry M (2014) In vitro antagonistic activity, plant growth promoting traits and phylogenetic affiliation of rhizobacteria associated with wild plants grown in arid soil. Front Microbiol 5:651

16. Etesami H, Maheshwari DK (2018) Use of plant growth promoting rhizobacteria (PGPRs) with multiple plant growth promoting traits in stress agriculture: Action mechanisms and future prospects. Ecotoxicol Environ Saf 156:225-246

17. Fadiji AE, Ayangbenro AS, Babalola $O O$ (2020) Metagenomic profiling of the community structure, diversity, and nutrient pathways of bacterial endophytes in maize plant. Antonie Van Leeuwenhoek 113(11):1559-1571

18. Fan B, Wang C, Song X, Ding X, Wu L, Wu H, Gao X, Borriss R (2018) Bacillus velezensis FZB42 in 2018: the Gram-positive model strain for plant growth promotion and biocontrol. Front Microbiol 9:2491

19. Franco-Correaa M, Quintanaa A, Duquea C, Suareza C, Rodrígueza MX, Bareab JM (2010) Evaluation of actinomycete strains for key traits related with plant growth promotion and mycorrhiza helping activities. Appl Soil Ecol 45:209-217

20. Gao JL, Xue J, Yan H, Tong S, Sayyar Khan M, Wang LW, Mao XJ, Zhang X, Sun JG (2019) Pantoea endophytica sp. nov., novel endophytic bacteria isolated from maize planting in different geographic regions of northern China. Syst Appl Microbiol 42(4):488-494

Page $7 / 15$ 
21. Gao Q, Yang M, Zuo Z (2018) Overview of the anti-inflammatory effects, pharmacokinetic properties and clinical efficacies of arctigenin and arctiin from Arctium lappa L. Acta Pharmacol Sin 39(5):787-801

22. Gong Y, Bai JL, Yang HT, Zhang WD, Xiong YW, Ding P, Qin S (2018) Phylogenetic diversity and investigation of plant growth-promoting traits of actinobacteria in coastal salt marsh plant rhizospheres from Jiangsu, China. Syst Appl Microbiol 41(5):516-527

23. Gordon SA, Weber RP (1951) Colorimetric estimation of indoleacetic acid. Plant Physiol 26(1):192

24. Hansen BL, Pessotti RC, Fischer MS, Collins A, El-Hifnawi L, Liu MD, Traxler MF (2020) Cooperation, competition, and specialized metabolism in a simplified root nodule microbiome. mBio 11(4):e01917-20

25. Hardoim PR, Van Overbeek LS, Berg G, Pirttila AM, Compant S, Campisano A, Doring M, Sessitsch A (2015) The hidden world within plants: ecological and evolutionary considerations for defining functioning of microbial endophytes. Microbiol Mol Biol Rev 79:293-320

26. Harman G, Khadka R, Doni F, Uphoff N (2021) Benefits to plant health and productivity from enhancing plant microbial symbionts. Front Plant Sci 11:610065

27. Hols P, Ferain T, Garmyn D (1994) Use of expression secretion signals and vector amylase and levanase expression. Appl Environ Microbiol 60:14011403

28. Huang C, Bu Y, Shan Z, Dai C (2016) Research advances in mechanisms of watermelon continuous cropping diseases and its biological control. Chin J Ecol 35:1670-1676

29. Jain R, Bhardwaj P, Pandey SS, Kumar S (2021) Arnebia euchroma, a plant species of cold desert in the Himalayas, harbors beneficial cultivable endophytes in roots and leaves. Front Microbiol 12:696667

30. Kaewkla O, Franco CM (2013) Rational approaches to improving the isolation of endophytic actinobacteria from Australian native trees. Microb Ecol 65:384-393

31. Kidd PS, Álvarez A, Álvarez-López V, Cerdeira-Pérez A, Rodríguez-Garrido B, Prieto-Fernández Á, Chalot M (2021) Beneficial traits of root endophytes and rhizobacteria associated with plants growing in phytomanaged soils with mixed trace metal-polycyclic aromatic hydrocarbon contamination. Chemosphere 277:130272

32. Kim OS, Cho YJ, Lee K, Yoon SH, Kim M, Na H, Park SC et al (2012) Introducing EzTaxon-e: a prokaryotic 16S rRNA gene sequence database with phylotypes that represent uncultured species. Int J Syst Evol Microbiol 62:716-721

33. Krechel A, Faupel A, Hallmann J, Ulrich A, Berg G (2002) Potato-associated bacteria and their antagonistic potential towards plant-pathogenic fungi and the plant-parasitic nematode Meloidogyne incognita (Kofoid \& White) Chitwood. Can J Microbiol 48(9): 772-786

34. Krishnamoorthy A, Agarwal T, Kotamreddy JNR, Bhattacharya R, Mitra A, Maiti TK, Maiti MK (2020) Impact of seed-transmitted endophytic bacteria on intra- and inter-cultivar plant growth promotion modulated by certain sets of metabolites in rice crop. Microbiol Res 241:126582

35. Lee SM, Kong HG, Song GC, Ryu CM (2021) Disruption of Firmicutes and Actinobacteria abundance in tomato rhizosphere causes the incidence of bacterial wilt disease. ISME J 15(1):330-347

36. Li WJ, Xu P, Schumann P, Zhang YQ, Pukall R, Xu LH, Stackebrandt E, Jiang CL (2007) Georgenia ruanii sp. nov., a novel actinobacterium isolated from forest soil in Yunnan (China) and emended description of the genus Georgenia. Int J Syst Evol Microbiol 57:1424-1428

37. Li X, Li B, Cai S, Zhang Y, Xu M, Zhang C et al (2020) Identification of rhizospheric actinomycete Streptomyces lavendulae SPS-33 and the inhibitory effect of its volatile organic compounds against Ceratocystis fimbriata in postharvest sweet potato (Ipomoea batatas (L.) Lam. Microorganisms 8:319

38. Li X, Zhao Z, Kuang P, Shi X, Wang Z, Guo L (2019) Regulation of lipid metabolism in diabetic rats by Arctium lappa L. polysaccharide through the PKC/NF-KB pathway. Int J Biol Macromol 136:115-122

39. Liotti RG, da Silva Figueiredo MI, da Silva GF, de Mendonça EAF, Soares MA (2018) Diversity of cultivable bacterial endophytes in Paullinia cupana and their potential for plant growth promotion and phytopathogen control. Microbiol Res 207:8-18

40. Lundberg DS, Lebeis SL, Paredes SH, Yourstone S, Gehring J et al (2012) Defining the core Arabidopsis thaliana root microbiome. Nature 488:86-90

41. Marag PS, Suman A (2018) Growth stage and tissue specific colonization of endophytic bacteria having plant growth promoting traits in hybrid and composite maize (Zea mays L.). Microbiol Res 214:101-113

42. Martínez-Romero E, Aguirre-Noyola JL, Taco-Taype N, Martínez-Romero J, Zuñiga-Dávila D (2020) Plant microbiota modified by plant domestication. Syst Appl Microbiol 43(5):126106

43. Mathur P, Roy S (2021) Insights into the plant responses to drought and decoding the potential of root associated microbiome for inducing drought tolerance. Physiol Plant 172(2):1016-1029

44. Mello IS, Targanski S, Pietro-Souza W, Frutuoso Stachack FF, Terezo AJ, Soares MA (2020) Endophytic bacteria stimulate mercury phytoremediation by modulating its bioaccumulation and volatilization. Ecotoxicol Environ Saf 202:110818

45. Mina D, Pereira JA, Lino-Neto T, Baptista P (2020) Epiphytic and endophytic bacteria on olive tree phyllosphere: exploring tissue and cultivar effect. Microb Ecol 80(1):145-157

46. Papik J, Folkmanova M, Polivkova-Majorova M, Suman J, Uhlik O (2020) The invisible life inside plants: deciphering the riddles of endophytic bacterial diversity. Biotechnol Adv 44:107614

47. Penrose DM, Glick BR (2003) Methods for isolating and characterizing ACC deaminase-containing plant growth-promoting rhizobacteria. Physiol Plant 118:10-15

48. Pereira SIA, Monteiro C, Vega AL, Castro PML (2016) Endophytic culturable bacteria colonizing Lavandula dentata L. plants: isolation, characterization and evaluation of their plant growth-promoting activities. Ecol Eng 87:91-97

Page $8 / 15$ 
49. Phour M, Sehrawat A, Sindhu SS, Glick BR (2020) Interkingdom signaling in plant-rhizomicrobiome interactions for sustainable agriculture. Microbiol Res 241:126589

50. Polivkova M, Suman J, Strejcek M, Kracmarova M, Hradilova M, Filipova A, Poly F, Monrozier LJ, Bally R (2001) Improvement in the RFLP procedure for studying the diversity of nifH genes in communities of nitrogen fixers in soil. Res Microbiol 152(1):95-103

51. Qin S, Chen HH, Zhao GZ, Li J, Zhu WY, Xu LH, Jiang JH, Li WJ (2012) Abundant and diverse endophytic actinobacteria associated with medicinal plant Maytenus austroyunnanensis in Xishuangbanna tropical rainforest revealed by culture-dependent and culture-independent methods. Environ Microbiol Rep 4(5):522-531

52. Qin S, Feng WW, Wang TT, Ding P, Xing K, Jiang JH (2017) Plant growth-promoting effect and genomic analysis of the beneficial endophyte Streptomyces sp. KLBMP 5084 isolated from halophyte Limonium sinense. Plant Soil 416:117-132

53. Qin S, Feng WW, Zhang YJ, Wang TT, Xiong YW, Xing K (2018) Diversity of bacterial microbiota of coastal halophyte Limonium sinense and amelioration of salinity stress damage by symbiotic plant growth-promoting actinobacterium Glutamicibacter halophytocola KLBMP 5180. Appl Environ Microbiol 84(19):e01533-18

54. Qin S, Li J, Chen HH, Zhao GZ, Zhu WY, Jiang CL, Xu LH, Li WJ (2009) Isolation, diversity, and antimicrobial activity of rare actinobacteria from medicinal plants of tropical rain forests in Xishuangbanna. China. Appl Environ Microbiol 75:6176-6186

55. Qin S, Miao Q, Feng WW, Wang Y, Zhu X, Xing K, Jiang JH (2015) Biodiversity and plant growth promoting traits of culturable endophytic actinobacteria associated with Jatropha curcas L. growing in Panxi dry-hot valley soil. Appl Soil Ecol 93:47-55

56. Qin S, Xing K, Jiang JH, Xu LH, Li WJ (2011) Biodiversity, bioactive natural products and biotechnological potential of plant-associated endophytic actinobacteria. Appl Microbiol Biotechnol 89(3):457-473

57. Qin S, Zhang YJ, Yuan B, Xu PY, Xing K, Wang J, Jiang JH (2014) Isolation of ACC deaminase-producing habitat-adapted symbiotic bacteria associated with halophyte Limonium sinense (Girard) Kuntze and evaluating their plant growth-promoting activity under salt stress. Plant Soil 374:753-766

58. Rana KL, Kour D, Kaur T, Devi R, Yadav AN, Yadav N, Dhaliwal HS, Saxena AK (2020) Endophytic microbes: biodiversity, plant growth-promoting mechanisms and potential applications for agricultural sustainability. Antonie Van Leeuwenhoek 113(8):1075-1107

59. Rashid S, Charles TC, Glick BR (2012) Isolation and characterization of new plant growth-promoting bacterial endophytes. Appl Soil Ecol 61:217-224

60. Rat A, Naranjo HD, Krigas N, Grigoriadou K, Maloupa E, Alonso AV, Schneider C, Papageorgiou VP, Assimopoulou AN, Tsafantakis N, Fokialakis N, Willems A (2021) Endophytic bacteria from the roots of the medicinal plant Alkanna tinctoria Tausch (Boraginaceae): exploration of plant growth promoting properties and potential role in the production of plant secondary metabolites. Front Microbiol 12:633488

61. Reysenbach A, Pace N (1995) Reliable amplification of hyperthermophilic archaeal 16S rRNA genes by the polymerase chain reaction. In: Robb F (ed) Archaea: a laboratory manual. Cold Spring Harbor Laboratory Press, Cold Spring Harbor, NY, pp 101-107

62. Ryan RP, Germaine K, Franks A, Ryan DJ, Dowling DN (2008) Bacterial endophytes: recent developments and applications. FEMS Microbiol Lett 278(1):1-9

63. Santoyo G, Moreno-Hagelsieb G, Orozco-Mosqueda Mdel C, Glick BR (2016) Plant growth-promoting bacterial endophytes. Microbiol Res 183:92-99

64. Saxena AK, Kumar M, Chakdar H, Anuroopa N, Bagyaraj DJ (2020) Bacillus species in soil as a natural resource for plant health and nutrition. J Appl Microbiol 128(6):1583-1594

65. Schwyn B, Neilands JB (1987) Universal chemical assay for the detection and determination of siderophore. Anal Biochem 160:47-56

66. Shirling EB, Gottlieb D (1966) Methods for characterization of Streptomyces species. Int J Syst Bacteriol 16:313-340

67. Song Z, Lu Y, Liu X, Wei C, Oladipo A, Fan B (2020) Evaluation of Pantoea eucalypti FBS135 for pine (Pinus massoniana) growth promotion and its genome analysis. J Appl Microbiol 129(4):958-970

68. Thomas P, Shaik SP (2020) Molecular profiling on surface-disinfected tomato seeds reveals high diversity of cultivation-recalcitrant endophytic bacteria with low shares of spore-forming Firmicutes. Microb Ecol 79(4):910-924

69. Tian XY, Zhang CS (2017) Illumina-based analysis of endophytic and rhizosphere bacterial diversity of the coastal halophyte Messerschmidia sibirica. Front Microbiol 8:2288

70. Ullah A, Nisar M, Ali H, Hazrat A, Hayat K, Keerio AA, Ihsan M, Laiq M, Ullah S, Fahad S, Khan A, Khan AH, Akbar A, Yang X (2019) Drought tolerance improvement in plants: an endophytic bacterial approach. Appl Microbiol Biotechnol 103(18):7385-7397

71. Vo QAT, Ballard RA, Barnett SJ et al (2021) Isolation and characterisation of endophytic actinobacteria and their effect on the growth and nodulation of chickpea (Cicer arietinum). Plant Soil 466:357-371

72. Vorholt JA, Vogel C, Carlström Cl, Müller DB (2017) Establishing causality: opportunities of synthetic communities for plant microbiome research. Cell Host Microbe 22(2):142-155

73. Wu W, Chen W, Liu S, Wu J, Zhu Y, Qin L, Zhu B (2021) Beneficial relationships between endophytic bacteria and medicinal plants. Front Plant Sci $12: 646146$

74. Xing K, Qin S, Bian GK, Zhang YJ, Zhang WD, Dai CC et al (2012) Pseudonocardia nantongensis sp. nov., a novel endophytic actinomycete isolated from the coastal halophyte Tamarix chinensis Lour. Antonie Van Leeuwenhoek 102:659-667

75. Xiong YW, Ju XY, Li XW, Gong Y, Xu MJ, Zhang CM, Yuan B, Lv ZP, Qin S (2020a) Fermentation conditions optimization, purification, and antioxidant activity of exopolysaccharides obtained from the plant growth-promoting endophytic actinobacterium Glutamicibacter halophytocola KLBMP 5180. Int $\mathrm{J}$ Biol Macromol 153:1176-1185 
76. Xiong YW, Li XW, Wang TT, Gong Y, Zhang CM, Xing K, Qin S (2020b) Root exudates-driven rhizosphere recruitment of the plant growth-promoting rhizobacterium Bacillus flexus KLBMP 4941 and its growth-promoting effect on the coastal halophyte Limonium sinense under salt stress. Ecotoxicol Environ Saf 194:110374

77. Xu W, Wang F, Zhang M, Ou T, Wang R, Strobel G, Xiang Z, Zhou Z, Xie J (2019) Diversity of cultivable endophytic bacteria in mulberry and their potential for antimicrobial and plant growth-promoting activities. Microbiol Res 229:126328

78. Yu X, Yang J, Wang E, Li B, Yuan H (2015) Effects of growth stage and fulvic acid on the diversity and dynamics of endophytic bacterial community in Stevia rebaudiana Bertoni leaves. Front Microbiol 6:867

79. Zhang Y, Li T, Liu Y, Li X, Zhang C, Feng Z, Peng X, Li Z, Qin S, Xing K (2019) Volatile organic compounds produced by Pseudomonas chlororaphis subsp. aureofaciens SPS-41 as biological fumigants to control Ceratocystis fimbriata in postharvest sweet potatoes. J Agric Food Chem 67(13):3702-3710

80. Zhuang L, Li Y, Wang Z, Yu Y, Zhang N, Yang C, Zeng Q, Wang Q (2021) Synthetic community with six Pseudomonas strains screened from garlic rhizosphere microbiome promotes plant growth. Microb Biotechnol 14(2):488-502

\section{Tables}

Table 1

Diversity estimations for endophytic bacterial communities within the four roots samples.

\begin{tabular}{|llllllll|}
\hline Samples & Reads & $\begin{array}{l}\text { OTUs } \\
(\mathbf{9 7 \% )}\end{array}$ & $\begin{array}{l}\text { Coverage } \\
(\mathbf{9 7 \%})\end{array}$ & \multicolumn{2}{c}{ Community richness } & Community diversity \\
\hline NB1_R & 35280 & 332 & 0.996429 & 529 & 641 & 0.315 & 2.07 \\
\hline NB2_R & 30292 & 449 & 0.995015 & 616 & 743 & 0.0722 & 3.56 \\
\hline NB3_R & 27380 & 494 & 0.994704 & 677 & 642 & 0.0522 & 4 \\
\hline NB4_R & 52573 & 221 & 0.998098 & 404 & 497 & 0.4137 & 1.7 \\
\hline
\end{tabular}

Table 2

Top ten most abundant genera of endophytic bacteria in the roots of Arctium lappa L. detected by HTS method.

\begin{tabular}{|c|c|c|c|c|c|c|c|c|}
\hline Top & NB1_R & & NB2_R & & NB3_R & & NB4_R & \\
\hline 10 & Genera & $\begin{array}{l}\text { Percentage } \\
(\%)\end{array}$ & Genera & $\begin{array}{l}\text { Percentage } \\
(\%)\end{array}$ & Genera & $\begin{array}{l}\text { Percentage } \\
(\%)\end{array}$ & Genera & $\begin{array}{l}\text { Percentage } \\
(\%)\end{array}$ \\
\hline 1 & Pantoea & 53.19 & Pseudomonas & 19.24 & Hyphomicrobium & 7.35 & Pseudomonas & 76.94 \\
\hline 2 & Streptomyces & 1.87 & Pantoea & 13.17 & Hydrogenophaga & 4.74 & Pantoea & 2.50 \\
\hline 3 & Hydrogenophaga & 1.66 & Streptomyces & 3.85 & Actinocorallia & 4.58 & Marinobacter & 1.81 \\
\hline 4 & Devosia & 1.12 & Methylotenera & 3.39 & Streptomyces & 3.98 & Arthrobacter & 1.47 \\
\hline 5 & Hyphomicrobium & 0.99 & Hydrogenophaga & 2.81 & Pseudomonas & 3.89 & Bacillus & 0.94 \\
\hline 6 & Pseudoxanthomonas & 0.96 & Bacillus & 2.64 & Ohtaekwangia & 3.56 & Acinetobacter & 0.34 \\
\hline 7 & Altererythrobacter & 0.93 & Solibacillus & 2.23 & Bacillus & 3.42 & Rahnella & 0.21 \\
\hline 8 & Rhizobium & 0.69 & Devosia & 1.84 & Acinetobacter & 3.19 & Vibrio & 0.14 \\
\hline 9 & Pseudomonas & 0.67 & Enterococcus & 1.76 & Solibacillus & 3.05 & Pseudoxanthomonas & 0.12 \\
\hline 10 & Ohtaekwangia & 0.53 & Ohtaekwangia & 1.70 & Polaromonas & 2.89 & Streptomyces & 0.12 \\
\hline
\end{tabular}


Table 3

Plant growth-promoting (PGP) traits of four selected endophytic bacteria.

\begin{tabular}{|c|c|c|c|c|}
\hline Strains / traits & WY035 & WY068 & WY297 & WY358 \\
\hline Origin & NB3_root & NB2_root & NB1_root & NB2_stem \\
\hline Genus & Bacillus & Pantoea & Pseudomonas & Microbacterium \\
\hline Phosphate solubilization & & + & + & + \\
\hline Growth on $\mathrm{N}$-free medium & + & + & + & + \\
\hline nifHgene & + & + & + & + \\
\hline Siderophore & + & & + & \\
\hline Ammonia production & + & & + & + \\
\hline $\begin{array}{l}\text { IAA production } \\
(\mathrm{mg} / \mathrm{L})\end{array}$ & & $37.797 \pm 6.722$ & $4.279 \pm 0.615$ & \\
\hline $\begin{array}{l}\text { ACC deaminase } \\
(\mathrm{nmol} \mathrm{a}-\mathrm{KA} / \mathrm{mg} \mathrm{Pr} \cdot \mathrm{h})\end{array}$ & & & & $4.779 \pm 0.247$ \\
\hline Xylanase & & & + & + \\
\hline Amylase & & & + & \\
\hline Protease & + & + & & + \\
\hline Cellulose & & & + & \\
\hline Chitinase & & & + & + \\
\hline
\end{tabular}

\section{Figures}

\section{A}

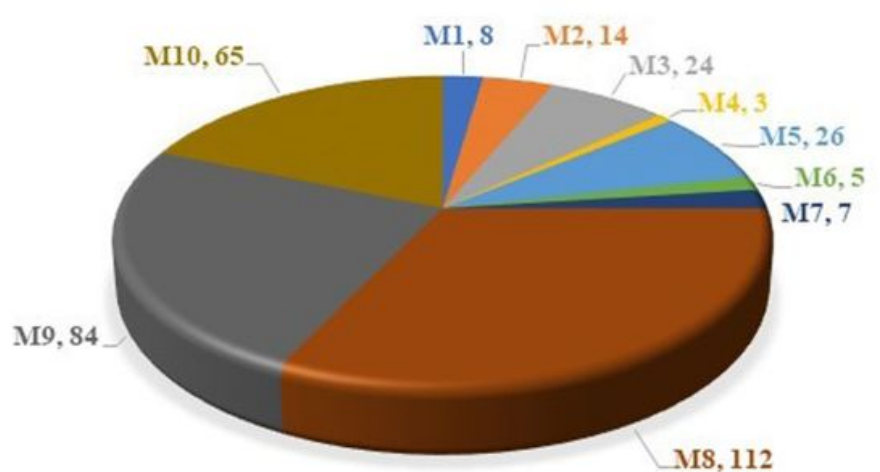

B

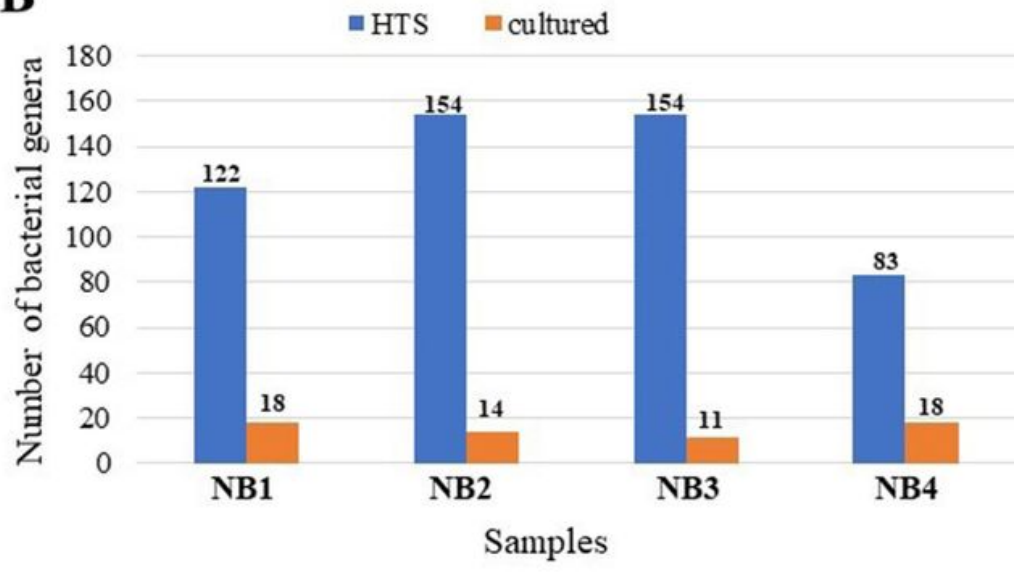

\section{Figure 1}

Numbers of endophytic bacteria obtained using different media (A), and comparison of the number of bacterial genera using cultured and high throughput sequencing (HTS) methods (B). Abbreviations in (A) correspond to media types listed in the materials and methods. 
A
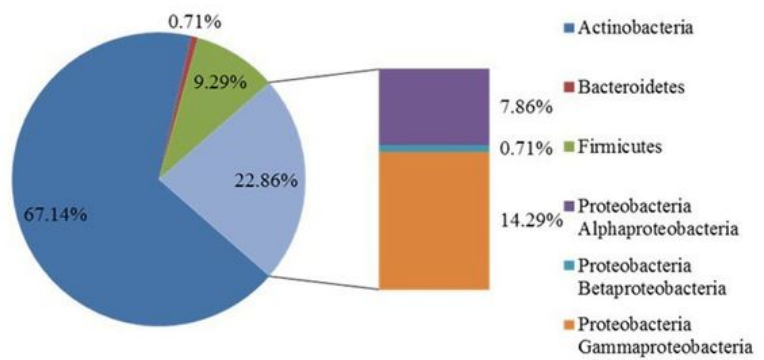

C

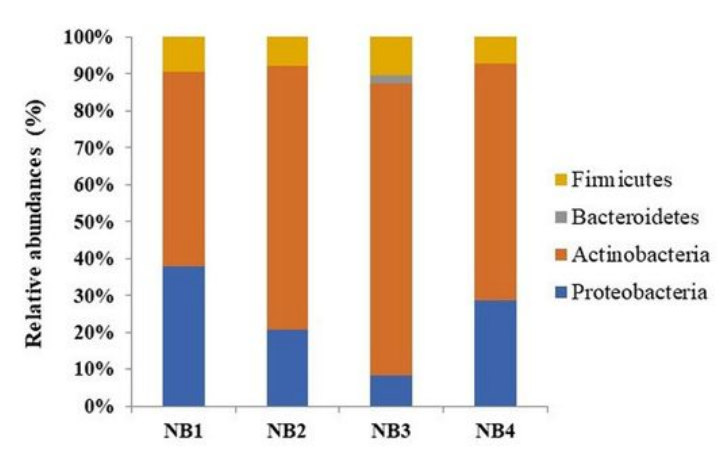

B

Proteobacteria

Firmicutes

Bacteroidetes

Actinobacteria

D

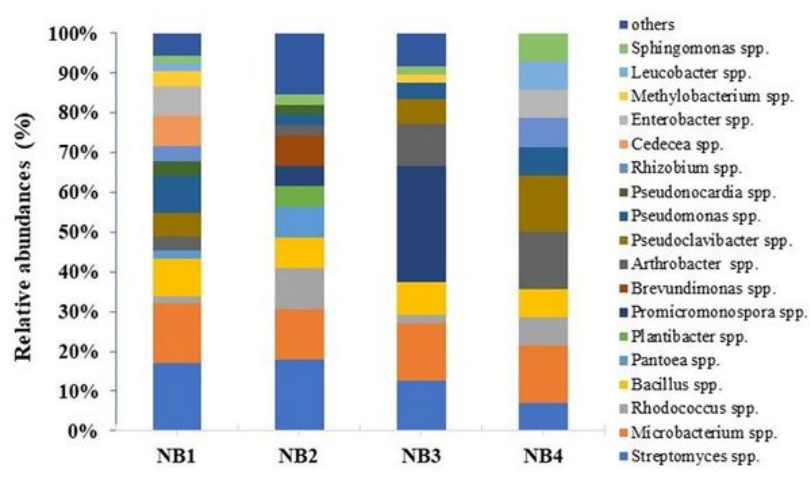

Figure 2

Diversity of the culturable endophytic bacteria from Arctium lappa L. (A), Distribution and number of isolates at the phylum level; (B), Distribution and number of isolates at the genus level; Relative abundances (\%) of endophytic bacteria from different cultivars at phylum (C) and genus (D) levels. 
$\mathbf{A}$

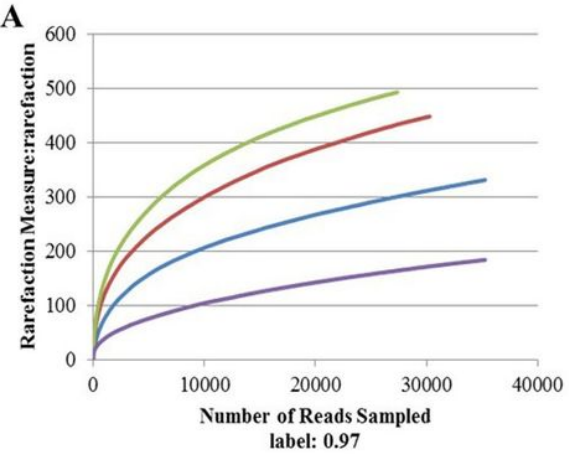

C

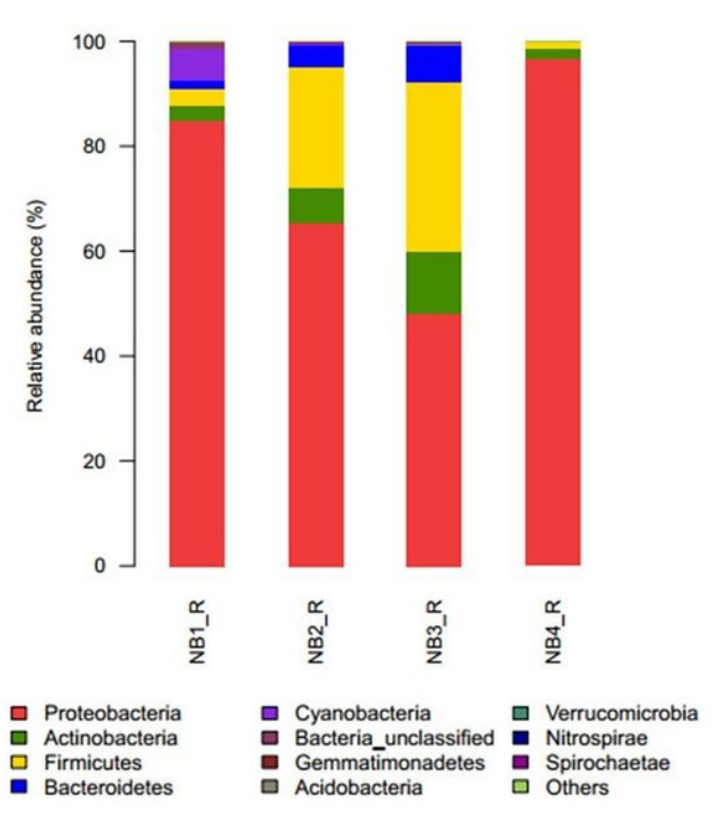

B
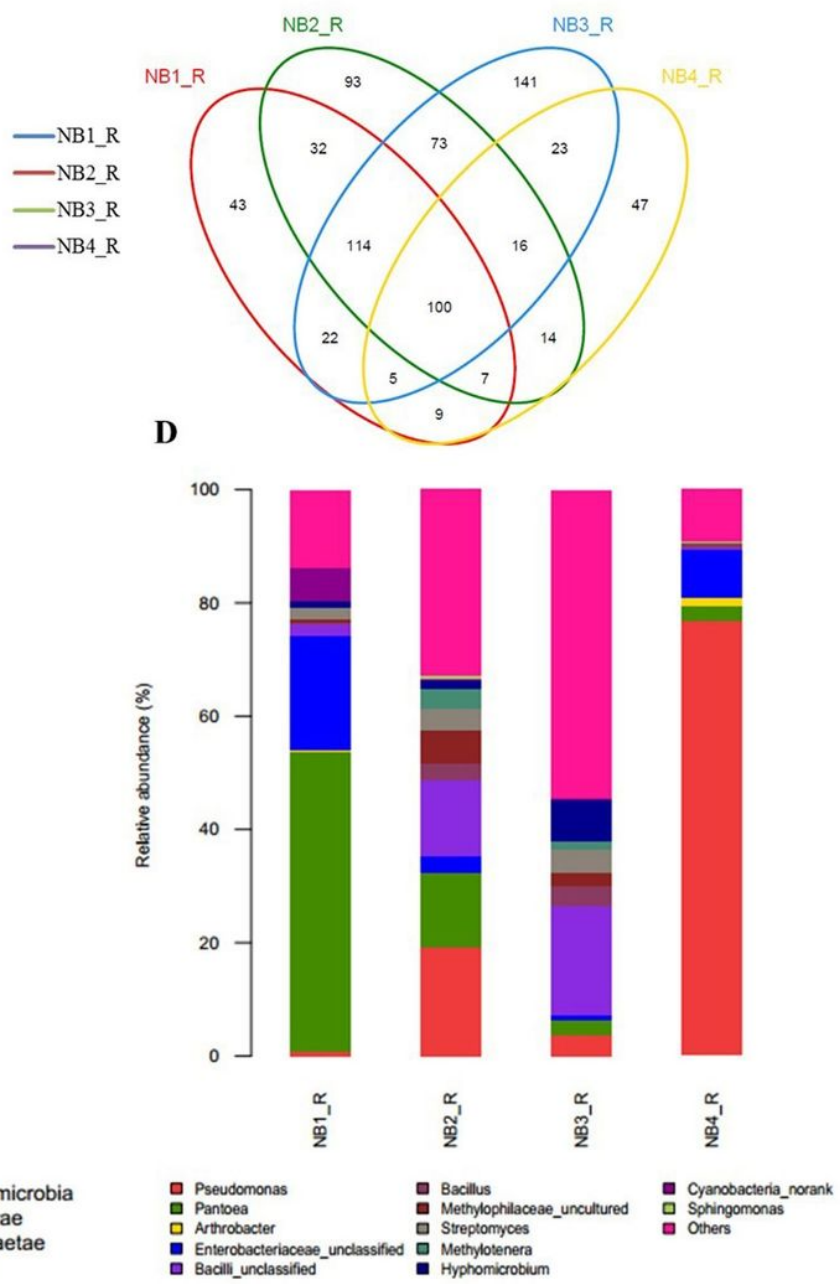

\section{Figure 3}

Statistical analysis of the OTUs by culture-independent method. Rarefaction curves (A) based on OTUs observed within four roots samples. The Venn diagram (B) grouping by cultivars shows the common and different OTUs for each sample. Relative abundances (\%) of the OTUs at phylum (C) and genus (D) levels. 
A
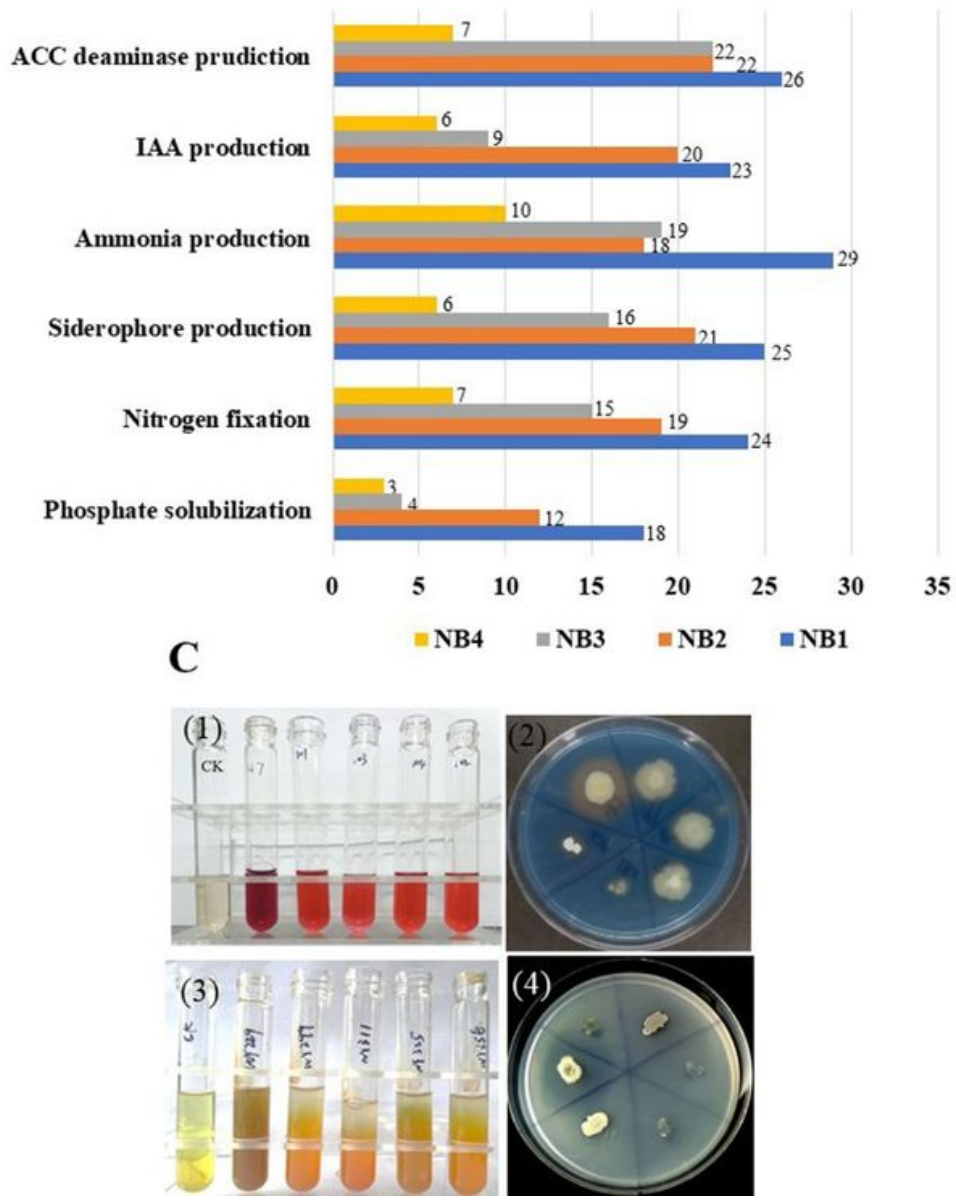

B
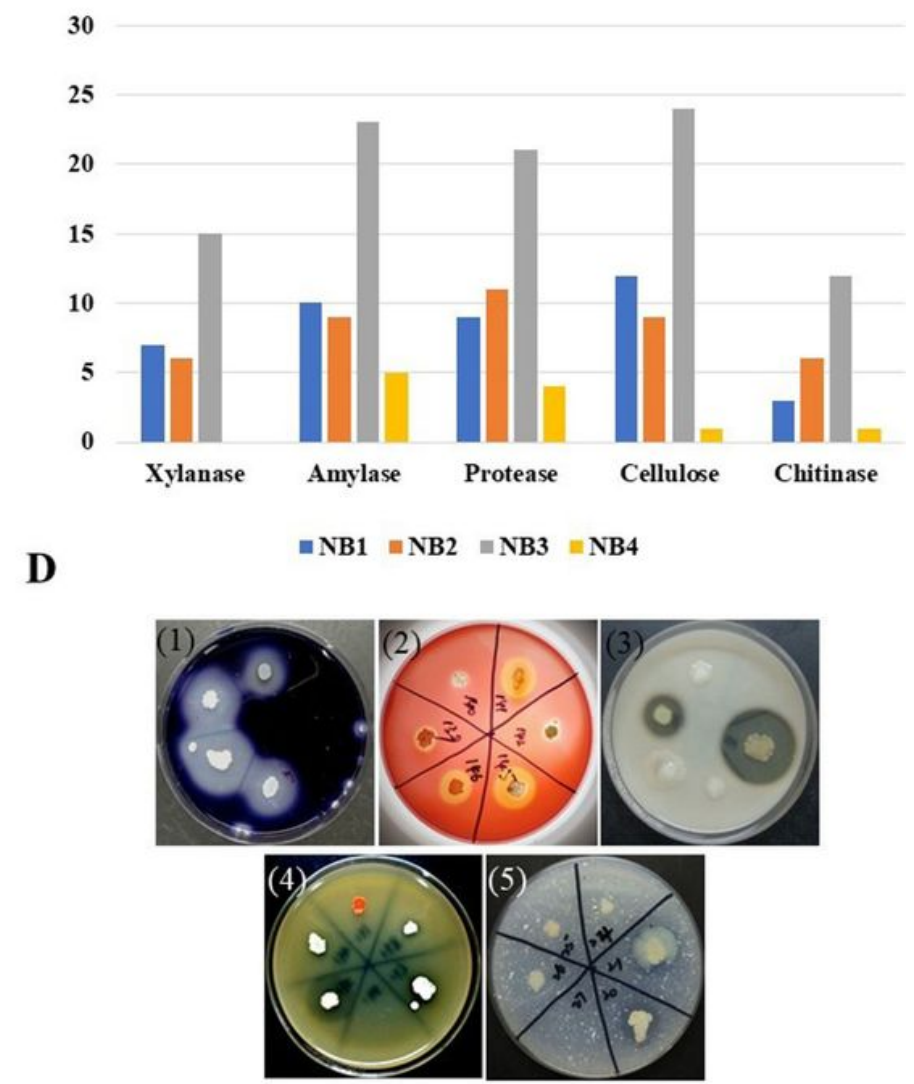

\section{Figure 4}

Number statistics of the active endophytic bacteria with different plant growth-promoting (PGP) traits (A) and different hydrolase (B), and the photos of positive reaction of the PGP traits (C, 1. IAA; 2. siderophore; 3. Ammonia; 4. Phosphate solubilization) and different hydrolase (D, 1. amylase; 2 . cellulose; 3. protease; 4. xylanase; 5 . chitinase) detection. 
A
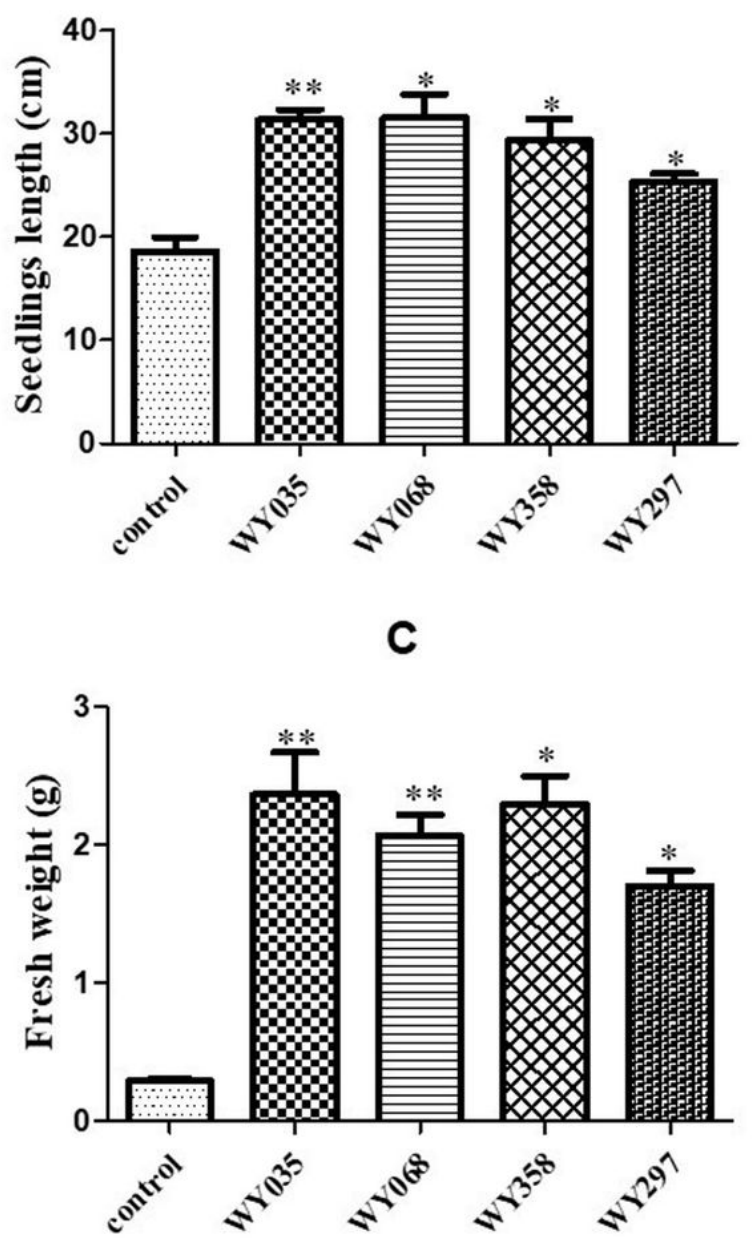

B

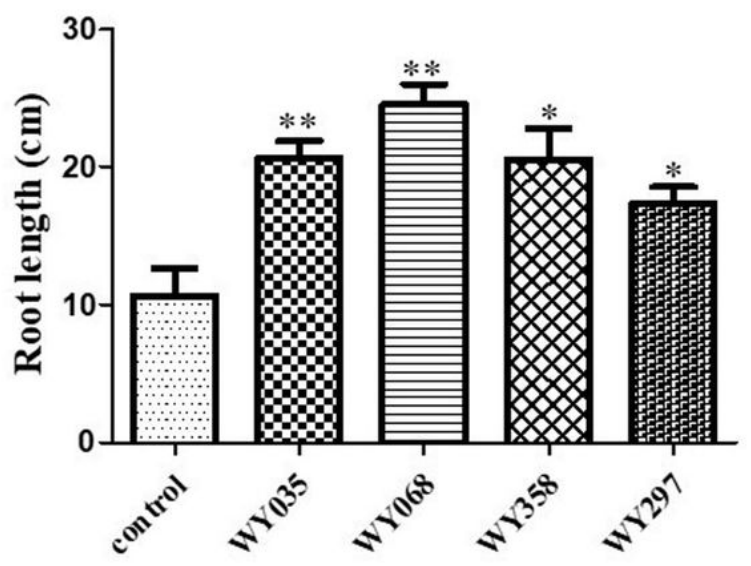

D

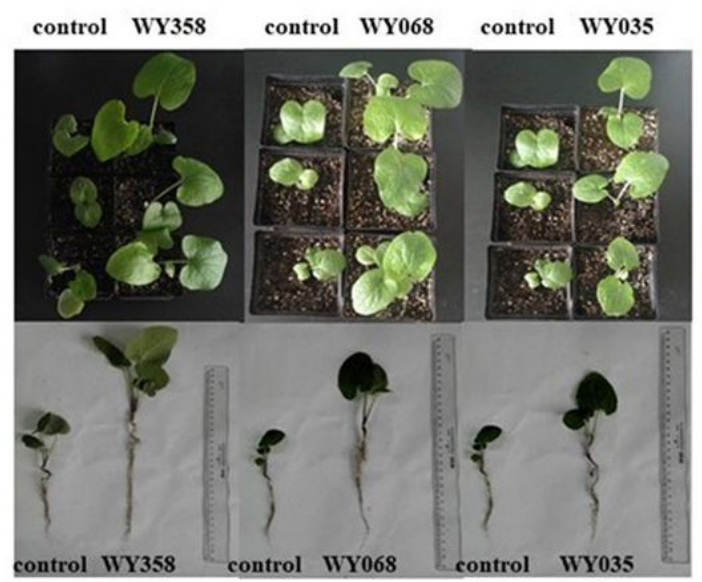

Figure 5

Effects of endophytic bacteria inoculation on the seedlings growth of Arctium lappa L., (A). seedlings length; (B). root length; (C). fresh weight; and (D) whole seedlings growth differences in control and endophytes treatments and the aerial part of the seedlings. The asterisk $\left({ }^{*}\right)$ and $(* \star)$ indicate $P<0.05$ and $P<0.01$ (t test) for each treatment versus control (five replicates).

\section{Supplementary Files}

This is a list of supplementary files associated with this preprint. Click to download.

- supplementarymaterial.docx 